\title{
Amorphous fiber based on the Fe-B-C molten system for bulk reinforcement of concrete
}

\author{
Artemiy Cherkashin ${ }^{1}$, Yasmin Begich ${ }^{1, *}$, Polina Sherstobitova ${ }^{1}$, and Oleg Tolochko ${ }^{2}$ \\ ${ }^{1}$ Peter the Great St. Petersburg Polytechnic University, Polytechnicheskaya 29, St. Petersburg, \\ 195251, Russian Federation
}

\begin{abstract}
The article deals with the use of amorphous fiber of the Fe-B-C system, which was obtained by spinning the melt. Comparative tests of the samples made on the basis of the test material on the compressive strength and tensile strength of the traditional destructive method were made. The conductivity of the samples was also tested. Physical and mechanical characteristics of the material are obtained.
\end{abstract}

\section{Introduction}

One of the most significant trends in construction is the disperse reinforcement of concrete with metal fibers. Due to the unique characteristics of these materials, the development of new types of fiber and the determination of their effect on physical characteristics, fibrocement has a promising value for the entire industry as a whole, as evidenced by the increased interest of scientists dealing with technical and economic problems in the use of building materials [1-3].

Products based on cement mortars with metal fibers have increased tensile strength, bending strength, shear strength, and impact resistance. The presence of reinforcing fibers leads to the achievement of crack resistance and improvement of structural integrity [4-8].

In addition, the use of fiber can significantly reduce the cost of building materials and construction of the building (structure) as a whole. This can be achieved by reducing the costs of reinforcement and concrete in reinforced concrete structures [9].

Based on already conducted studies [10-14], we can conclude that today the main issue remains optimization of geometric parameters and physical properties of fibers, which are determined by the need to ensure a reliable adhesion of the fibers to the cement matrix under permitted loads, and also to resist the tensile forces [15-17].

The interphase connection between the fiber and the matrix is very important, it helps counteract the shear stress transmitted between the cement matrix and the fibers at the interface. As adhesion increases, the results of cement composites become more durable and elastic [18]. This can be achieved using a light amorphous fiber of a flat cross section. Concrete reinforced with such fibers possesses increased crack resistance, frost resistance, corrosion resistance and resistance to impact loads. These indicators are 1.5-2.5 times higher than for conventional reinforced concrete [19].

\footnotetext{
* Corresponding author: yasmin1010@yandex.ru
} 
An analysis of recent studies [20-24] has shown that there are many works devoted to the study of metallic fibers of circular cross section, while amorphous fibers of a flat section remain poorly studied.

Based on the foregoing, it can be concluded that the purpose of this study is to determine the influence of amorphous metallic fibers on the physical and mechanical properties of cement composites.

Research set the following tasks:

1. Perform tests of cement samples with the addition of amorphous-metallic fiber obtained at the department "Technology and research of materials" of the Institute of Metallurgy, Machine Building and Transport of the Polytechnic University of Peter the Great.

2. Determine the optimal percentage of adding this fiber to the cement slurry to obtain the best physical and mechanical characteristics of the samples.

\section{Methods}

A multicomponent amorphous metal alloy (metallic glass) of the Fe-BC system with Mo content (up to $20 \%$ by weight), Cr (up to $17 \%$ ), and V (6\%) obtained at the Department of Technology and research materials "Institute of Metallurgy, Mechanical Engineering and Transport Polytechnic University of Peter the Great was used as a fiber material.

Initial ingots of multicomponent alloys with a mass of 40-50 gr. were obtained in quartz crucibles using an HFC (high-frequency current) setup. Melting was carried out in stages. In the first stage, the components of the alloy $\mathrm{Co}, \mathrm{Fe}, \mathrm{C}, \mathrm{B}$ melted in a certain weight ratio in a vacuum, then the crucible was filled with an inert gas, then hardly soluble alloying additives were added to the melt in order of their reactivity $(\mathrm{Cr}, \mathrm{Mo}, \mathrm{V})$. Overheating at 200-500 ${ }^{\circ} \mathrm{C}$ from the melting temperature ensured complete dissolution of the components and a fairly uniform structure of the alloy.

Fig. 1 shows a schematic diagram of an experimental apparatus for producing fiber. The apparatus for obtaining amorphous fiber works as follows: a sample of the test material is placed in a quartz crucible and melted with an inductor. The upper part of the crucible is connected to the high-pressure inert gas supply system, and the lower part is made in the form of a capillary. After the metal melts, the required gas pressure in the crucible $(\Delta p)$ is created and the melt is squeezed out as a thin (fraction of a millimeter) of the trickle onto the disc rotating at a speed $\mathrm{Vd}$. The disk is made of copper and rotates at a speed that provides a linear surface speed, and, consequently, the speed of receiving the tape to $50 \mathrm{~m} /$ s. The jet of the alloy, incident at a speed $\mathrm{Vg}$ at an angle $\alpha$ to the surface, results in the formation of a stationary melt pool on the surface of the cooler disk [24]. The spinning process is equivalent to the continuous extraction of the tape from the bottom of this puddle.

The melt quickly hardens at the edge of the disk, resulting in a continuous tape a few tens of micrometers thick. The width of the formed ribbon depends on the width of the capillary at the bottom of the crucible. The entire device is placed in a vacuum chamber with a gas pressure that is adjustable within a wide range. The cooling rate of the melt is estimated from various data as $104-106 \mathrm{~K} / \mathrm{s}$.

This method of producing amorphous metallic alloys in the form of thin tapes by superfast cooling of the melt on the surface of a rotating cold disc or drum is called "melt spinning technique". 


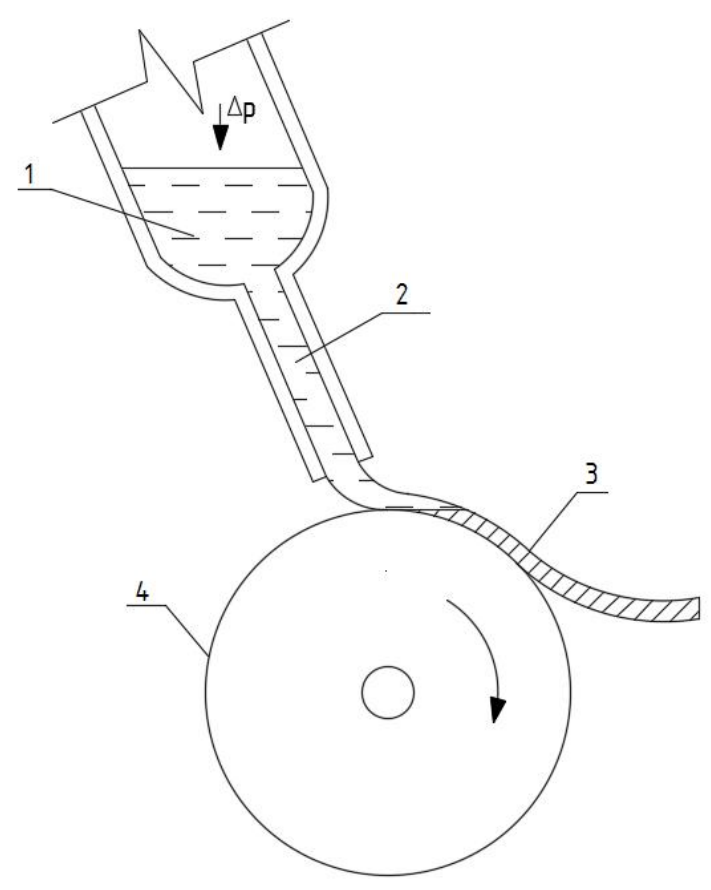

Fig. 1. Scheme of the spinning process. 1 - molten metal, 2 - jet of melt, 3 - amorphous metal fiber, 4 - cold drum

The method of spinning a melt was studied in detail by many authors. In various modifications it can be used both for research purposes and for the industrial production of amorphous ribbons of various alloys.

It should be noted that the amorphous fiber has a large lateral surface, as compared to the wire, which is one of the main reserves of increasing the strength of fiber-reinforced concrete, the destruction of which in most cases occurs as a result of pulling the fibers out of the concrete matrix. Moreover, the cross-sectional shape of the fiber, due to the manufacturing process, provides considerable rigidity of such fiber, as well as a uniform distribution of the fibers in the volume, and, consequently, a significant improvement in the physical and mechanical characteristics of the steel fiber-reinforced concrete [25-28].

To obtain test samples - beams 40x40x160 mm in size, a solution mixture of normal density was laid in a three-sectional form fixed on a standard vibrating pad and compacted by vibration. For the first 24 hours samples were stored in molds in a room with high humidity, then the beams pulled out of the molds were kept in water at a temperature $(20 \pm$ 2) ${ }^{\circ} \mathrm{C}$.

To produce a control test specimen the following compound was used: $500 \mathrm{~g}$ of cement (PC 500 D0), 1500g standard uniform sand and 240ml water. Pre-mixing of sand and cement was carried out in a spherical cup manually, then automatically in a slurry mixer. The water-cement ratio for all compositions of the steel-fiber-concrete mixture is 0.48 .

Method of preparation of the control mortar mix was also used in the manufacture of test beams with fiber in which certain amount of cement was replaced with fiber respectively $(0.5 \% ; 1 \% ; 1.5 \% ; 2 \% ; 3 \%)$. After achieving a uniform distribution of the fiber in the cement-sand mixture, water was added.

Tests of the specimens were performed in accordance with Russian State Standard GOST 310.4-81. "Cements. Methods for determination of flexural strength and 
compression". Beams were tested for their tensile and compressive strength on the $3^{\text {rd }}, 7^{\text {th }}$ and $28^{\text {th }}$ days after their production. The results are shown in Table 1.

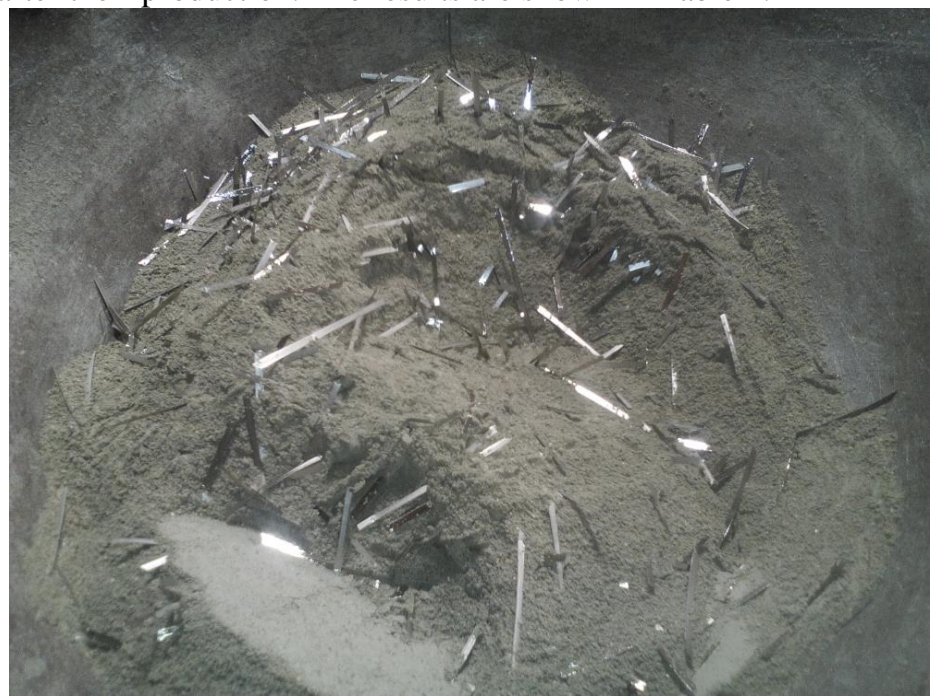

Fig. 2. Amorphous fiber in the mixing stage with a cement-sand composition

In addition, the electrical conductivity of the sample was tested, the results are shown in Table 2.

The tests were carried out using a Resipod device - a fully integrated 4-point Wenner sensor designed to measure the specific electrical resistance of concrete or stone.

During operation, a current is applied to the two external sensors and the potential difference between the two internal sensors is measured.

The resistivity of concrete is determined by the resistance of the fluid in the pores, the structure of the pores and the degree of saturation.

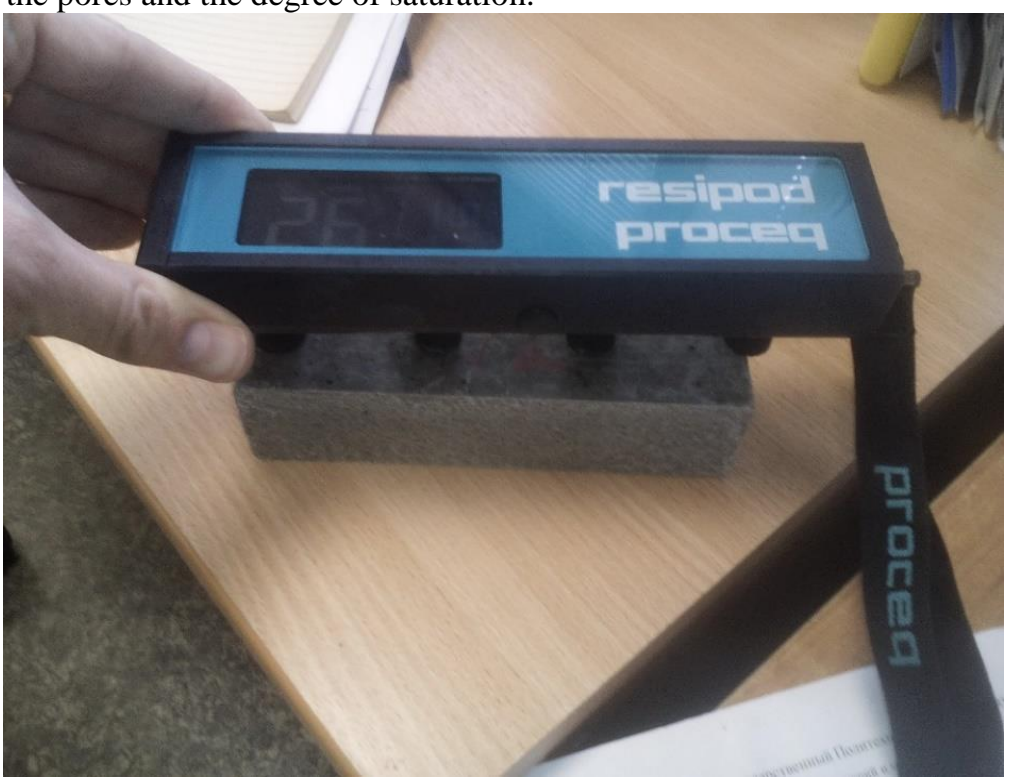

Fig. 3. Measurement of electrical conductivity by means of Resipod device 


\section{Experimental results and discussion}

It is known that the physical and mechanical characteristics of the fibers depend on a large number of factors, one of which is the distribution of the fiber in the cement-sand matrix. Fiber distribution pattern is affected by the length, diameter and mass of the fiber, as well as the percentage of fiber reinforcement and the presence of anchors.

When using the standard method of compaction samples by vibration the fiber is distributed parallel to the wide side. Due to the fact that the sample was turned over to flat surfaces - bending occurs on the thin side of the fiber, which can be seen in Fig. 4.
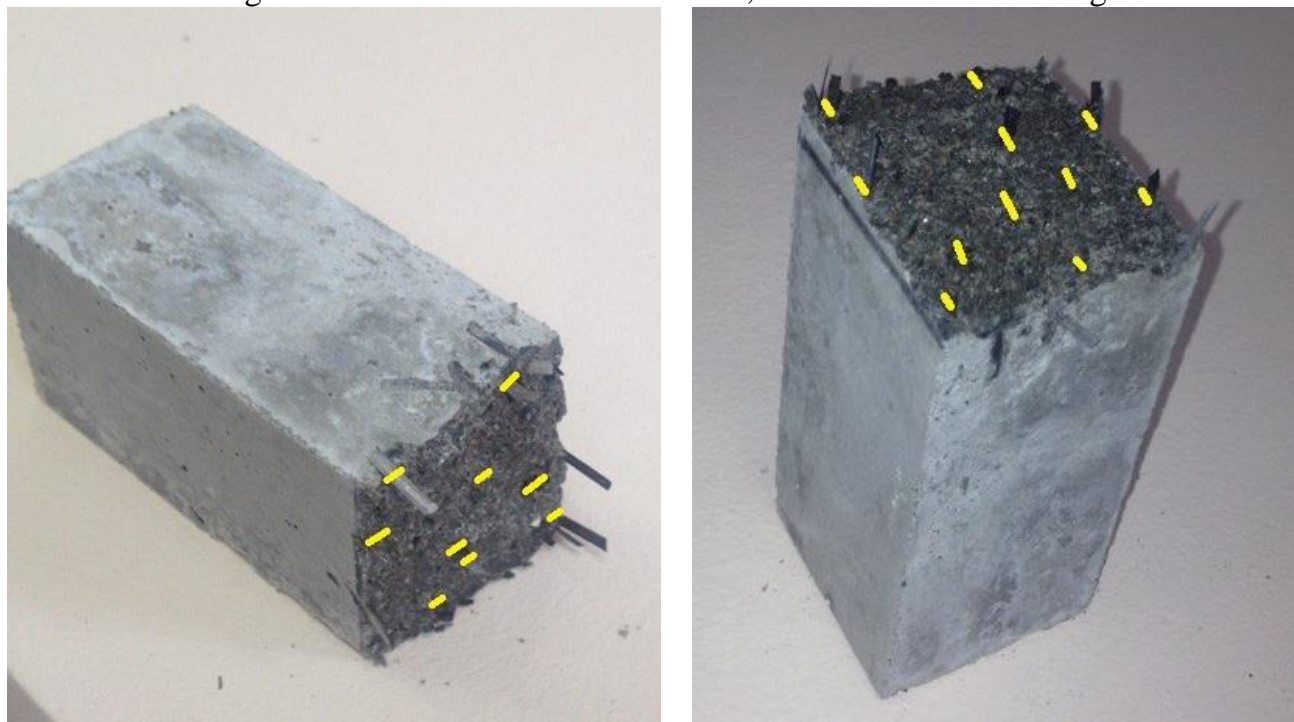

Fig. 4. The parallel distribution of the fiber in the sample

Destruction of samples reinforced with amorphous metallic fiber occurs as a result of fiber rupture, which indicates the full use of their strength characteristics.

The data below states (Tab. 1) that noticeable improvement of the tensile strength (Fig. 5 ) was demonstrated by the specimens that contained $3 \%$ of fiber. Nevertheless, the compressive strength was worsened (Fig. 6).

According to the test results, it can be concluded that the addition of fiber leads to an increase in tensile strength by $55.9 \%$, and the compression strength decreases by $30 \%$ compared to the control sample.

Destruction of samples reinforced with amorphous metallic fiber occurs as a result of fiber rupture, which indicates the full use of their strength characteristics.

The results obtained are in good agreement with the data of [25-26], which demonstrate an increase in the strength characteristics of cement composites when amorphous fibers are added to them. 
Table 1. Compressive and tensile strength of the specimens

\begin{tabular}{|c|c|c|c|c|c|c|}
\hline \multirow{2}{*}{$\begin{array}{c}|c| \\
\text { № }\end{array}$} & \multicolumn{2}{|c|}{3} & \multicolumn{2}{|c|}{ Age, days } \\
\cline { 2 - 7 } & $\begin{array}{c}\text { Tensile } \\
\text { strength } \\
(\mathrm{Rt}), \\
\mathrm{MPa}\end{array}$ & $\begin{array}{c}\text { Compressive } \\
\text { strength } \\
(\mathrm{Rc}), \mathrm{MPa}\end{array}$ & $\begin{array}{c}\text { Tensile } \\
\text { strength } \\
(\mathrm{Rt}), \\
\mathrm{MPa}\end{array}$ & $\begin{array}{c}\text { Compressive } \\
\text { strength } \\
(\mathrm{Rc}), \mathrm{MPa}\end{array}$ & $\begin{array}{c}\text { Tensile } \\
\text { strength } \\
(\mathrm{Rt}), \\
\mathrm{MPa}\end{array}$ & $\begin{array}{c}\text { Compressive } \\
\text { strength } \\
(\mathrm{Rc}), \mathrm{MPa}\end{array}$ \\
\hline $\begin{array}{c}\text { Control } \\
\text { specimen }\end{array}$ & 7.0 & 37.5 & 8.2 & 50.4 & 8.6 & 60.2 \\
\hline $\begin{array}{c}0.5 \% \\
\text { fiber }\end{array}$ & 6.5 & 33.1 & 7.7 & 49.9 & 8.8 & 60.7 \\
\hline $\begin{array}{c}1.0 \% \\
\text { fiber }\end{array}$ & 7.4 & 34.0 & 7.4 & 49.5 & 9.2 & 59.2 \\
\hline $\begin{array}{c}1.5 \% \\
\text { fiber }\end{array}$ & 8.7 & 33.1 & 8.8 & 47.1 & 9.8 & 57.5 \\
\hline $\begin{array}{c}2.0 \% \\
\text { fiber }\end{array}$ & 8.7 & 30.5 & 9.8 & 45.7 & 10.5 & 56.6 \\
\hline $\begin{array}{c}3.0 \% \\
\text { fiber }\end{array}$ & 8.9 & 26.9 & 12.1 & 43.9 & 13.9 & 51.0 \\
\hline
\end{tabular}

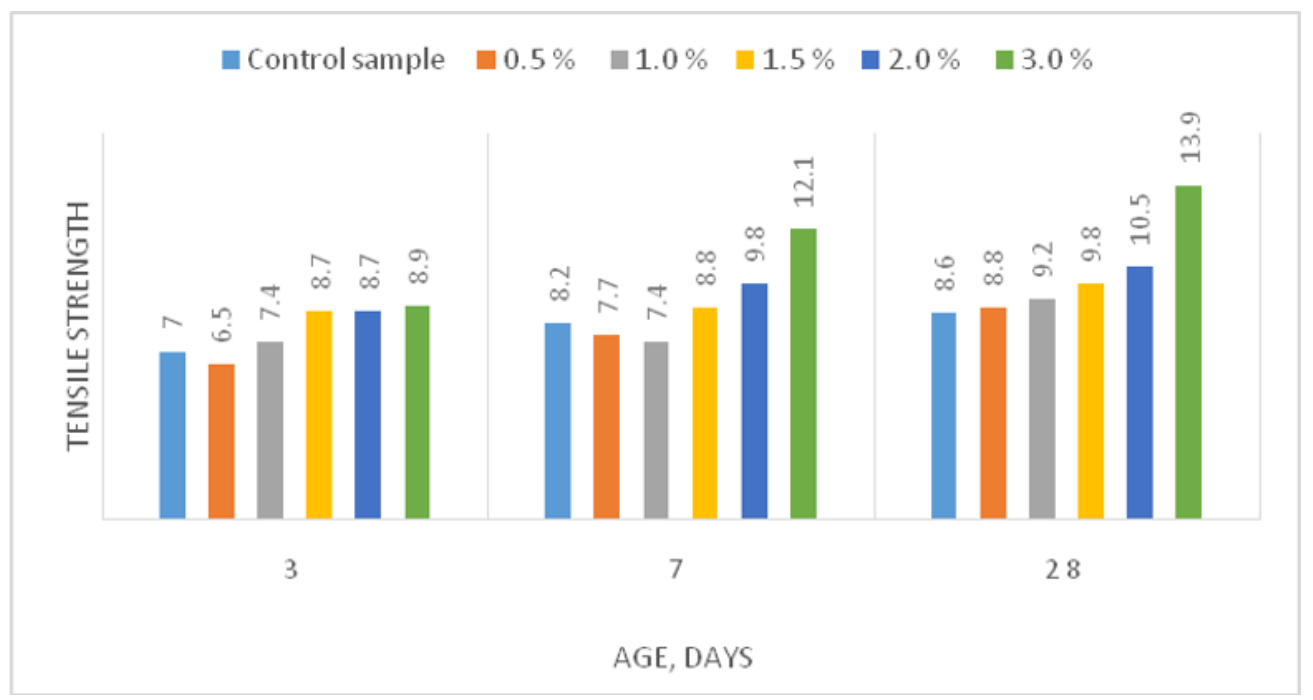

Fig. 5. Tensile strength of the specimens 


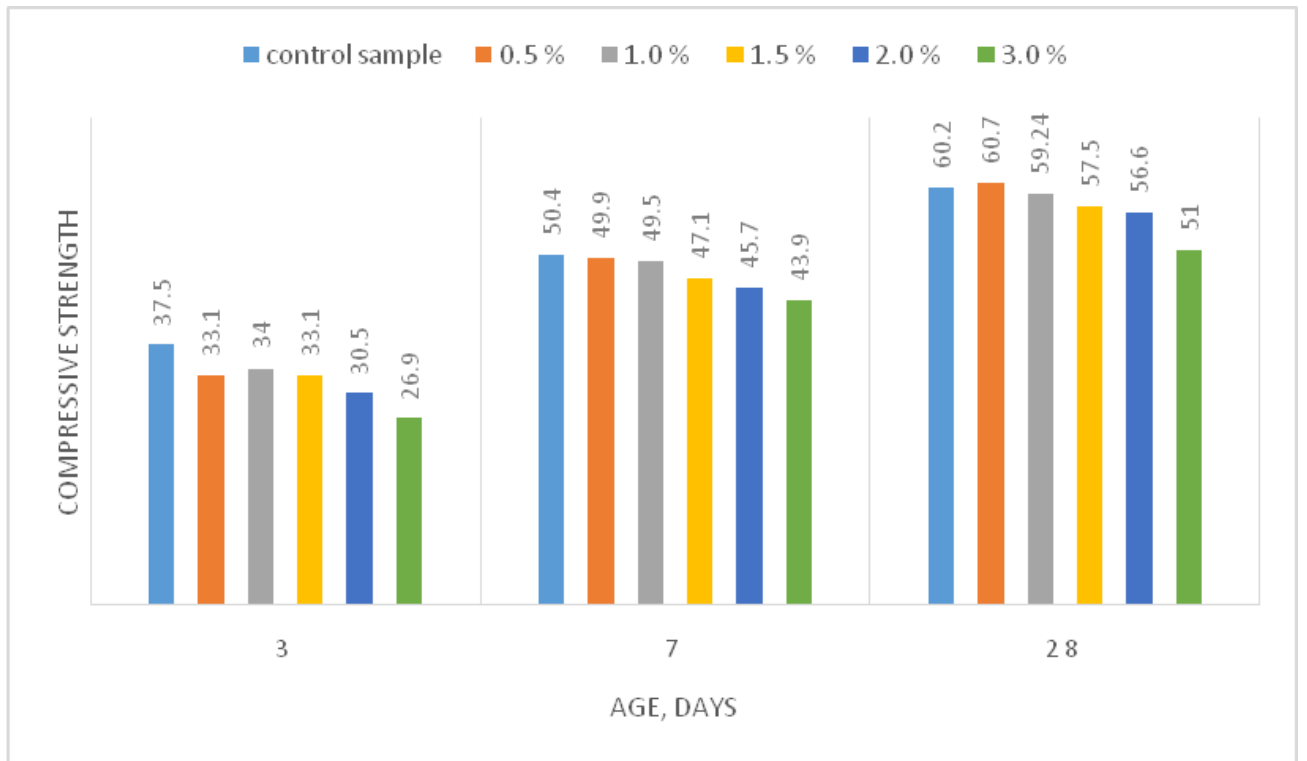

Fig. 6. Compressive strength of the specimens

Thus, the introduction of amorphous metallic fiber, which has a high adhesion to the matrix, leads to an increase in the strength and deformation characteristics of the composite.

Table 2. Results of tests for electrical conductivity

\begin{tabular}{|c|c|}
\hline № (\%) & $\begin{array}{c}\text { Conductivity, } \\
\mathrm{kOm} * \mathrm{~cm}\end{array}$ \\
\hline Control specimen & 30 \\
\hline $0.5 \%$ fiber & 17.1 \\
\hline $1.0 \%$ fiber & 8.2 \\
\hline $1.5 \%$ fiber & 3.1 \\
\hline $2.0 \%$ fiber & 2.7 \\
\hline $3.0 \%$ fiber & 2.2 \\
\hline
\end{tabular}

Thus, the introduction of amorphous-metallic fibers leads to an increase in the electrical conductivity of the samples.

\section{Conclusions}

At this stage of the study of the amorphous microfiber of the Fe-B-C system in the composition of cement composites, we can draw the following conclusions:

1. Adding fiber at different concentrations to the cement composite leads to an increase in bending resistance by 55.9\%, and reduces the compressive strength by $30 \%$ compared to the control sample;

2. The addition of fiberglass prevents the spread of large cracks; there are numerous, but very narrow and usually harmless cracks;

3. Tests showed that the best physical and mechanical characteristics showed samples with the addition of $3 \%$ fiber to the cement slurry;

4. Due to compaction of the samples by vibration during the manufacturing, as well as due to the geometric characteristics of the amorphous fiber [31-34], it is aligned in parallel in one direction, which will not occur in real conditions, in the production of fiberreinforced concrete, where it will lie in several directions; 
5. When the concentration of fiber in the cement mixture is increased (which may be necessary when using only the fiber reinforcement of the structure and eliminating the core reinforcement), special measures should be provided to ensure the uniform distribution of the fiber in the structure;

6. The introduction of amorphous-metallic fiber increases the electrical conductivity of the samples;

7. In the future, it is important to conduct tests to determine the corrosion resistance of fiber and compare the amorphous fiber of the Fe-B-C system with other types of fibers;

8. Moreover, it is important to determine the possibility of using the fiber of the Fe$\mathrm{B}-\mathrm{C}$ system to reduce the percentage of core reinforcement of the slabs, since they are more likely to work on bending.

At this stage, it can be concluded that the Fe-B-C alloy is technologically and promising for the production of fiber used in the production of fiber cement.

\section{References}

1. N. Nikitin, Innovative development of modern science (2015)

2. Yu. Puharenko, D. Panteleev, M. Zhavoronkov, Bulletin of Civil Engineers, 1, 172176 (2017)

3. K. Talantova, Proceedings of Higher Educational Institutions. Machine Building, 8, 99-106 (2014)

4. N. Banthia, N. Nandakumar, Cem. Concr. Compos., 25 (1), 3-9 (2003)

5. U. Magdeev, V. Morozov, Yu. Pukharenko, Proceedings of the KSUAE, 1, 110-117 (2012)

6. C. Quan, Stroeven, Cem. Concr. Compos., 22 (4) (2000)

7. G. Xu, S. Magnani, D. Hannant, ACI Mater J., 95 (6) (1998)

8. S. Klyuev, A.Klyuev, A. Abakarov, E. Shorstova, N. Gafarova, Mag. of Civil Engineering., 7, 66-75 (2017)

9. I. Voilokov, Mag. Civ. Eng., 8, 6-8 (2009)

10. M. Gabidullin, R. Rakhimov, I. Badertdinov, A. Gabidullina, O. Stoyanov, All materials. Encycl. Reference, 3, 11-18 (2014)

11. S. Klyuev, Mag. Civ. Eng., 8, 61-66 (2012)

12. B. De Guillebon, M. Henry, G. Le Gal, C. Tete, Materials Science and Engineering, 98, 539-542 (1988)

13. P. Sukontasukkul, P. Jamsawang, Construction and Building Materials, 29, 201-205 (2012)

14. R. Lesovik, S. Klyuev, Mag. Civ. Eng., 3, 41-47 (2012)

15. A. Bentur, S. Mindess, Fibre reinforced cementitious composites (2014)

16. A. Borisyuk, Yu. Zyatyuk, Bulletin of the Belarusian-Russian University, 3, 160-168 (2016)

17. V. Travush, D. Konin, A. Krylov, Mag. Civ. Eng., 3, 36-44 (2018)

18. A. TaheriFard, H. Sokheli, S. Ramzani Movafah, F. Ahmadi, Mag. Civ. Eng., 2, 2631 (2016)

19. N. Shuvalov, Modern scientific research and innovation, 11, 10 (2017)

20. V. Shumikhin, A. Verkhovlyuk, V. Lakhnenko, A. Scheretsky, V. Casting Proc, 6, 67-70 (2009) 
21. V. Travush, D. Konin, A. Krylov, Mag. Civ. Eng., 1, 90-100 (2018)

22. T. Nizina, A. Balykov, Mag. Civ. Eng., 2, 13-25 (2016)

23. A. Korneev, O. Buzina, A. Sukhanov, I. Shipulin, Basic Research, 3, 506-511 (2016)

24. A. Tonitzki, A.N. Skvortsova, T.S. Koltsova, S.V. Ganin, M.A. Danilova, A.I. Shamshurin, St. Petersburg State Polytechnic University Journal of Engineering Science and Technology, 3(249), 81-88 (2016)

25. V. Afroughsabet, T. Ozbakkaloglu, Construction and building materials, 94, 73-82 (2015)

26. V. Roshchin, A. Roshchin, Basics of the production of nanocrystalline and amorphous metals (2009)

27. Yu. Puharenko, Bulletin of Civil Engineers, 1, 86-91 (2005)

28. Yu. Puharenko, Bulletin of Civil Engineers, 3, 80-93 (2008)

29. Yu. Puharenko, Bulletin of Civil Engineers, 2, 162-166 (2012)

30. Yu. Puharenko, D. Panteleev, M. Zhavoronkov, Academia, Architect. and constr., 2, 143-147 (2018)

31. J. Won, J. Lee, S. Lee, Composite Structures, 133, 117-123 (2015)

32. Yu. Puharenko, D. Panteleev, M. Zhavoronkov, Academia, Architect. and constr., 1, 107-111 (2016)

33. V. Dorf, R. Krasnovsky, D. Kapustin, K. Rogachev, V. Turkin, Concrete Techn., 10, 44-46 (2013)

34. T.Yu. Boykova, V.A. Dolgopolov, Teoriya i Praktika Fizicheskoy Kultury (2014)

35. V.Yu. Volkov, L.M. Volkova, N.G. Lutchenko, Teoriya i Praktika Fizicheskoy

Kultury (2014) 